\title{
Presentación
}

\section{Experiencias de literacidad en un mundo complejo: de la teoría a la práctica, de la práctica a la teoría}

\author{
GREGORIO HERNÁNDEZ ZAMORA* \\ GiANNINA OLIVIERI PACHECO** \\ MónicA MARÍA MÁRQuez Hermosillo***
}

$\mathrm{E}$

n un mundo de vertiginosos cambios, complejo y rico en información y comunicación, han de trascenderse las visiones simplistas, reductivas y fragmentarias sobre las experiencias implicadas en la lectura y la escritura. Ante panoramas desoladores en este campo, urge expandir el significado que se le otorga a leer y escribir, ensanchar la idea común sobre el texto y profundizar en las implicaciones que esto tiene para un mundo globalizado y polarizado al mismo tiempo.

Así, resulta urgente ampliar la mirada sobre las realidades dialógicas, textualizadas ahora de forma dinámica, y generar un conocimiento de alto orden sobre las experiencias de literacidad emergentes, capaces de dar cuenta de los cruces entre esta y los diversos campos de la interacción humana, así como de sus relaciones potenciales.

Con intención transformativa, el término de literacidad enriquece los conceptos de alfabetización y lectoescritura empleados tradicionalmente. Supone la inclusión de elementos como los valores sociales del autor y el lector, el contexto sociocultural en el que se inscriben, el sentido de la representación del mundo que se construye alrededor del texto, así como los procesos de mediación que ayudan a articular un discurso oral o escrito.

El término literacidad, junto con el de cultura escrita, es cada vez más usado y adoptado en todos los ámbitos académicos hispanohablantes, donde diversos autores los proponen por considerar que abren un panorama mucho más rico y útil para comprender las realidades del uso del lenguaje en una sociedad en movimiento.

Con el propósito de seguir abonando a la construcción de la noción de literacidad, se presentan en este número 56 de Sinéctica las aportaciones de educadores, lingüistas, psicólogos, trabajadores comunitarios, artistas, pedagogos, comunicadores y profesionales de distintos ámbitos que han centrado

Recuperado de: https://sinectica.iteso.mx/index.php/SINECTICA/article/view/1257

doi: 10.31391/S2007-7033(2021)0056/001

\footnotetext{
* Doctor en Lengua y Cultura Escrita por la Universidad de California en Berkeley. Profesor-investigador en la Universidad Autónoma Metropolitana. Pertenece al Grupo Latinoamericano de Especialistas en Alfabetización y Cultura Escrita y al Consejo Mexicano de Investigación Educativa. Líneas de investigación: conexiones entre lengua, cultura y cognición, con especial enfoque en cuestiones de desigualdad educativa, brechas en el aprendizaje y el funcionamiento de los discursos dominantes en educación.

** Doctora en Educación por la Universidad de Sevilla y en Historia por la Universidad Católica Andrés Bello, Venezuela. Directora de la Escuela de Letras de la Universidad Católica Andrés Bello. Participa en el proyecto de investigación "Artefactos culturales que favorecen el desarrollo de las competencias de literacidad" en el Instituto Tecnológico y de Estudios Superiores de Occidente (ITESO). Líneas de investigación: enseñanza de la lengua, análisis del discurso e historia política venezolana.

*** Doctora en Innovación Educativa por el Instituto Tecnológico de Estudios Superiores de Monterrey. Directora de Información Académica del ITESO. Líneas de investigación: literacidad, lectura y escritura, tecnologías para el aprendizaje e innovación educativa.
} 
su trabajo de investigación y de incidencia en experiencias de literacidad; unas veces partiendo de la teoría a la práctica y otras llevando el ingrediente empírico hacia una construcción de base teórica.

Confirmando el cariz transversal y transdisciplinar de la literacidad, los lectores encontrarán en este número de Sinéctica una diversidad de escenarios, metodologías y perspectivas en este campo de relativamente reciente abordaje y centrado en objetos con un alto grado de subjetividad y dinamismo, como lo son la expresión oral, la escritura, la lectura, la textualidad y sus combinaciones.

Algunos de los artículos publicados en este número se enfocan en los procesos de literacidad funcional; en ellos se destaca el desarrollo de las habilidades, competencias y disposiciones para el ejercicio de la lectura y la escritura implicadas en la vida familiar, escolar, laboral o social.

Otros artículos, centrados en la literacidad crítica, analizan los procesos de su adquisición, así como el desarrollo de la capacidad analítica, reflexiva y crítica a partir de los distintos usos del lenguaje, que evidencian realidades de distribución del conocimiento y del poder en la sociedad contemporánea.

Finalmente, otra de las perspectivas que se destaca en esta selección de artículos es la de la literacidad cultural, la cual refleja la influencia del contexto social, cultural, político, económico e histórico, que forman un todo y se insertan en las nuevas textualidades y prácticas del siglo XXI.

Ojalá que este diálogo entre experiencias de literacidad, que constituye en sí mismo una experiencia de literacidad académica, aporte a la reflexión, el análisis y al debate en torno a las diversas literacidades que nos rodean. Esperamos que, además, con ello se contribuya a la conformación de nuevas comunidades de intercambio de saberes y vivencias de literacidad, pues solo en colaboración será posible visualizar como horizonte la transformación de los procesos de aprendizaje, de las relaciones sociales y la posibilidad de desarrollo de la capacidad de agencia de los sujetos. 